\title{
Engine Intake Throttling for Active Regeneration of Diesel Particle Filters
}

\author{
A. Mayer, Th. Lutz, Chr. Lämmle, M. Wyser, F. Legerer \\ TTM, ETHZ, EMPA, BUWAL, AKPF
}

Copyright (C) 2003 SAE International

\section{ABSTRACT}

By means of catalysts, either coatings or fuel-borne, the temperature level for triggering the combustion of soot stored in particulate traps can be lowered from $600^{\circ} \mathrm{C}$ to $300^{\circ} \mathrm{C}$, in case of CRT even to $250^{\circ} \mathrm{C}$; but even that may fail, if in dense traffic application of a city-bus only $150-200^{\circ} \mathrm{C}$ are attained - similar situations of low load duty cycles exist in most other applications too. Mere passive regeneration may then not be sufficient, active support is needed.

This paper presents an "active" method applicable to any Diesel engine to increase the exhaust temperature whenever required: load of Diesel engines is controlled by the fuel flow only; consequently, excess of air above stochiometric requirement is increasing from $\lambda$ $=1.5$ to $\lambda=8$ with decreasing load, which is in fact the principal cause of the low temperature at light loads. By throttling the air flow simultaneously with the fuel flow, $\lambda$ is reduced leading to an increased temperature of the exhaust gas, which can be as high as 300 Centigrade.

The paper reports an investigation of intake air-flow throttling as an active tool to increase the exhaust temperature whenever needed for regeneration of a particulate filter by means of a computational simulation as well as an experimental verification concluding that throttling downstream of the turbocharger compressor will be the most advisable method.

Influence on fuel economy remains negligible because of the very short operation time.

Fast responding actuators are required to take care of rapid load changes.

Operation strategy can be electronically based on engine map data, but also more simple solutions are possible which are well suited to retrofit engines of older pure mechanical design.

It is recommended to use air intake throttling in combination with catalytic coating of particle filters or fuel borne catalysts to cover a very wide range of engine applications and operation conditions.

\section{INTRODUCTION}

Soot collected within a filter has to be burnt off periodically to prevent clogging of the trap; however, the required temperature-level of this combustion is about $500^{\circ} \mathrm{C}-600^{\circ} \mathrm{C}$; even this range may vary considerably according to composition, morphology, graphitized structure of the soot and due to the composition of the exhaust gas itself.

Such high temperature levels are rarely achieved by supercharged vehicle Diesel engines. Hence, measures have to be applied, either by reducing the ignition temperature, for instance by means of some catalyst (either a coating or fuel borne as an additive) and/or the temperature of the exhaust gas has to be increased. Nowadays, by means of catalytic methods levels of soot ignition temperatures may be lowered to about $250^{\circ} \mathrm{C}-350^{\circ} \mathrm{C}$; this covers a great number of operational conditions. Even then however, it may occur that vehicles are used in such a way that engines operate for an extended period of time at even lower load, such that the filter is clogging with well known consequences of high back pressure, as there are loss of power, increased fuel consumption, increased temperature-changes and thermal stresses on structural components; finally there is an uncontrolled burn-off at high load of soot, bringing about peak temperatures exceeding $1000^{\circ} \mathrm{C}$, endangering trap materials.

\section{REGENERATION REQUIREMENTS}

As soon as the back pressure sensor indicates that the load on the trap has reached the level for initiating regeneration the temperature level of the exhaust gas has to be increased for starting up the regeneration process. Rate of the chemical reaction should be kept within some limits, in order to prevent overheating of the filter material due the heat generated by the exothermal reaction. This can be done by means of an upper bound on the energy supply or by limiting the oxygen-content or by a combination of both. On the other hand, if layers of hardly inflammable soot as formed by slow deposition or interrupted regenerations are to be burnt, ignition may be enhanced by means of increased oxygen in excess, which may even be a necessity in case of pyrolysis of the filter cake. On one hand, regeneration should be short while on the other hand the process should be such that no damage occurs to the filter; further, combustion should be complete such that the time average of the back 
pressure which should be regarded as load of the filter on the engine should be minimised. Further, one has to postulate, that during regeneration no supplementary toxic substances (secondary emissions) are released. Finally, the engine operation, power and torque, must not be impeded due to this process and the operator must not notice any intervention into the engine operation.

\section{CURRENT SYSTEMS}

Presently, the required heat release is usually obtained by using burners or electric heaters.

An early attempt to increase the exhaust temperature by means of throttling the exhaust was made by Pattas [1]. Hot gas was retained within the cylinder; hence, supply of fresh air for combustion was reduced leading to increased temperature of the exhaust. Internal soiling of the cylinders and increase of thermal loads on structural components however should not be underestimated. Pattas method has not found wide application, problems of practical design may have contributed as well: flaps just at the hottest spot of the engine.

Throttling the air intake is not unknown either; this was for instance introduced by Nashar and Mayer [2] in the context of COMPREX supercharging with the aim of controlling exhaust recycling of pressure wave machines in an open cycle. The aspects of control were extensively analysed by Amstutz $[3,4]$. This method is less demanding, easier to build and from the viewpoint of control superior to throttling in hot gas.

Meanwhile, throttling of intake is widely applied for control of exhaust re-circulation. In a simple way the required pressure difference is obtained for controlling the flow volume of the exhaust to the intake [5]

\section{CONCEPT OF INTAKE THROTTLING}

The proposed method is based on the fact of very high an excess-air $(\lambda=6-8)$ of diesel engines at part load operation; only then, at part load there exists the problem of such conditions insufficient for regeneration. This high excess of air is consequence of torque and power control of Diesel engines by means of changing fuel dosage only without any control of air flow. Reducing thereby pumping losses and lowering heat losses contributes to the favourable fuel economy of the Diesel engine over the Sl-engine. However, as may be immediately apparent from the balance of enthalpies, combustion temperature is reduced, which basically constitutes a disadvantage from the viewpoint of quality of combustion; hence, undesirable emission components like $\mathrm{CO}$ and hydrocarbons not completely burnt at such light loads, are increasing.

By reducing the air flow at a given load, the ratio of air to fuel is shifted towards the stochiometric value, and temperature of exhaust-gas increases. Basically, it is feasible to achieve at part load temperature-levels close to full load operation - as an option $\lambda$ could also be reduced to a level optimal for low emission combustion.
Further, increased heat flow through cylinder-walls should be considered if internal temperatures are raised, and consequently enthalpy-flow of exhaust will somewhat decrease as compared to the case not throttled.

The dynamics of throttling-control is essential for a trouble-free operation of a vehicle engine; this means the following: if sudden acceleration is required a change of load occurs, starting from a throttled operation to full load, the required increase of air flow has to be released immediately, without any delay. Concepts of control, suitable for solving this problem have been described in detail in references [2] and [3].

While throttling a substantial depression is generated at the intake side, hence, there is an increased fuel consumption as a consequence. As the duration of this operational condition is limited to only some 10 minutes within 8 hours of operation, one may consider the overall effect as nearly negligible.

\section{COMPUTATIONAL SIMULATION.}

In order to analyse mechanisms of control of a wide variety of questions relating to alternate designs a computational simulation study was performed at the Department of Internal Combustion Engines at the Federal Polytechnic Institute, Zurich.

Design parameters were chosen such that they corresponded to a real engine at the Department's test bench; mathematical modeis could be verified by labmeasurements.

\section{The engine}

\begin{tabular}{|l|r|}
\hline Number of cylinders & 4 \\
\hline Number of valves per cylinder & 2 \\
\hline Bore $\quad[\mathrm{mm}]$ & 122 \\
\hline Stroke $[\mathrm{mm}]$ & 142 \\
\hline Displacement $\quad[$ [itre] & 6.64 \\
\hline Ratjo of compression & 17.2 \\
\hline Nominal power [kW] at engine rpm & $180 / 2100$ \\
\hline Max.torque [Nm] at engine rpm & $1050 / 1150-1500$ \\
\hline Supercharged & TC with IC \\
\hline Injection-system & Common-Rail \\
\hline EGR & None \\
\hline
\end{tabular}

Table1: Principal features of a modern turbo-charged Diesel-engine with common rail injection system.

\section{Computational model.}

Commercial software, GT-Power, was used as a base for setting up the model of the thermodynamic process. Flow phenomena in intake- and exhaustsystem are completely taken into account, hence the influence of throttling at any point of the system can be analysed.

The high pressure process element was modelled as a dual zone-part, using simplified models for combustion and thermal wall flow losses. Modelling of the low- 
pressure part was done by means of the onedimensional basic equation of gas-dynamics.

Characteristics of turbine and compressor of the turbocharger were supplied by the manufacturer as measured; they were implemented into the computational model.

In order to experimentally analyse design alternates (before compressor, after compressor, before turbine) a throttling flap was installed at suitable positions. By changing the flap-angle and simultaneously adjusting fuel mass flow, it was feasible to operate the engine at constant excess air of $\lambda=2$ at various part loads, while engine speed were kept constant.

Data of this experiment were used to validate the computational model at an average load of BMEP $=10,5$ bar. Temperatures, pressures, pressure-time developments within the cylinders were available. Pressure indication enabled determination of energy release of combustion at some points of reference which served as calibration input for validation. Based on measured data of this point of operation, data for even lower loads were obtained by means of extrapolation.

\section{Throttling before turbo-compressor}

The easiest way to install a flap is at the intake of the compressor. The following diagram exhibits the principal result, the change of exhaust temperature due to throttling; in this particular case presented for an average point of operation at $1400 \mathrm{rpm}$, load was stepwise reduced from almost full load to low part load at $\mathrm{BMPE}=1$ bar at constant air excess.

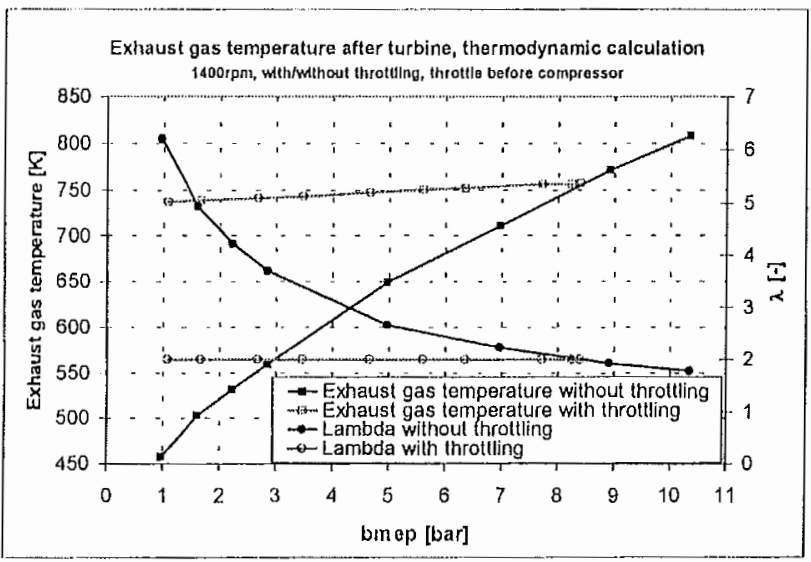

Fig. 1: Temperatures of exhaust gas with and without throttling for constant air excess before compressor at $1400 \mathrm{rpm}$ (computational model).

At customary operation $\lambda$ increases from $\lambda=2$ to $\lambda=$ 6 - 8 with decreasing load, which brings about a reduction of the exhaust temperature from more than $800^{\circ} \mathrm{K}$ to less than $450^{\circ} \mathrm{K}$. However, by throttling to a pre-determined level of $\lambda$ (in this particular case $\lambda=$ 2) the exhaust temperature may be almost kept constant. Comparing thermal states at low loads, BMEP = 1 bar exhibits very impressively an increase of exhaust temperatures by about 300 Centigrade.
The phenomenon already mentioned, an increase of loss due to heat transfer through the walls is to be seen from the following diagram.

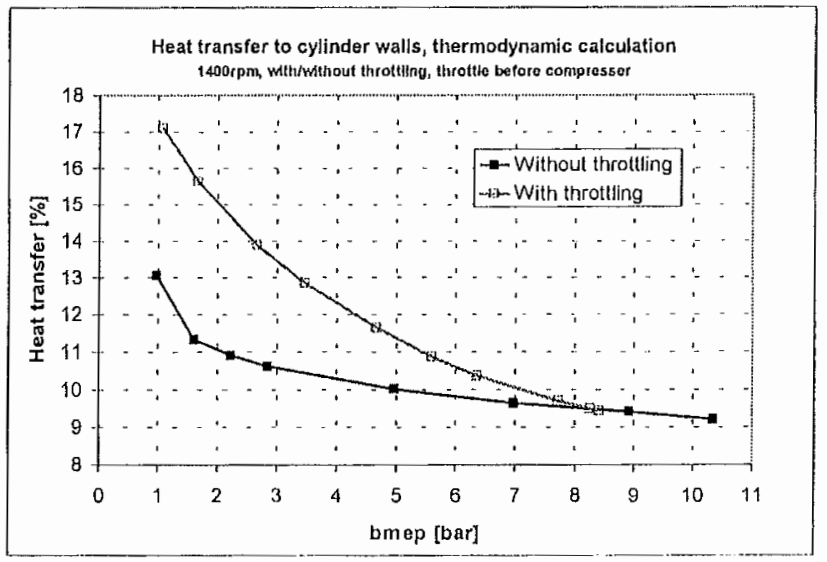

Fig.2: Losses due to heat transfer through cylinder walls while throttling before compressor (computational model).

As throttling is setting in relative loss due to heat transfer through the wall is increasing from $13 \%$ at full load up to $17 \%$ at the extreme part load, a phenomenon, clearly to be noticed yet not important from the overall viewpoint.

Obviously, throttling will cause an increase of the specific fuel consumption due to increased pumping work as seen in fig. 3 :

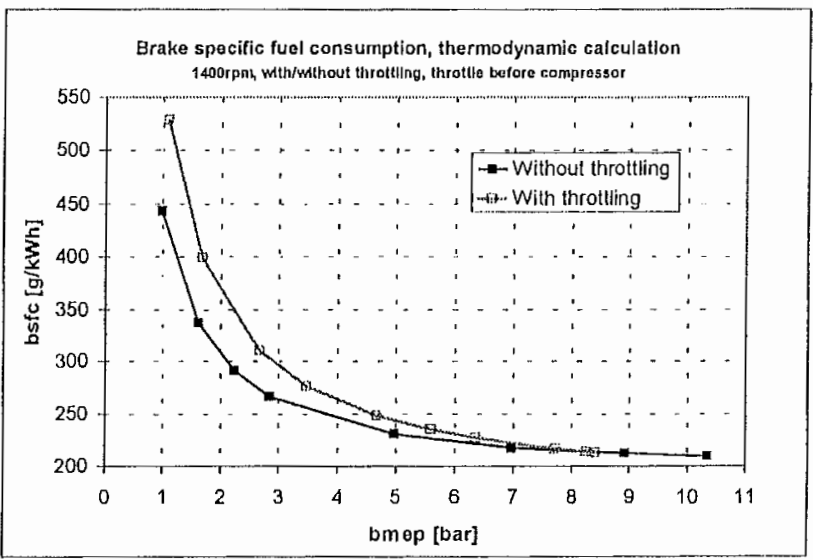

Fig. 3: Specific fuel consumption as a function of load with/without throttling (computational model);

With decreasing load the difference becomes apparent and it reaches at lowest loads $80 \mathrm{~g} / \mathrm{kWh}$, which considered for itself has to be regarded as a substantial loss; however, averaged over the time of the total process the effective additional fuel consumption is negligible, since throttling occurs only during a few minutes of a full working day at part load conditions. 


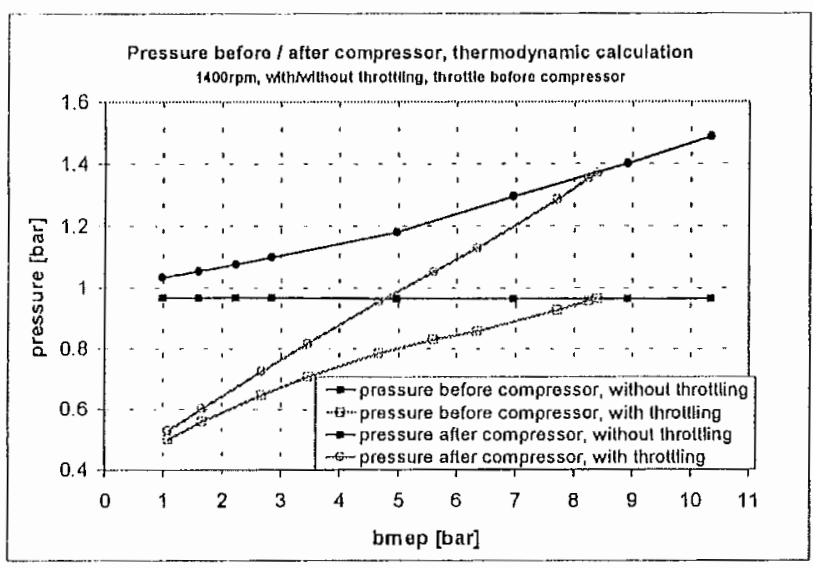

Fig.4: Pressure before/after compressor, with and without throttling (computational model).

In fig.4 pressures before and after turbocharger with and without throttling are presented as a function of load. Pressure before compressor is almost constant, i.e. more or less the ambient pressure; while the pressure between throttle and compressor intake decreases substantially. In order to achieve the intended effect of reduced air flow pressure prior to compressor has to drop to about 0.5 bar; pressureratio at the throttle has to reach almost 2 , within the slot of the flap the air flow reaches velocity of sound, a hint for the required mechanical strength of the flap.

Furthermore, the exceptional low pressure level leaves open some conjecture that this level may even extend to the rear of the compressor-wheel thereby influencing oil-sealing, hence, causing a risk of loosing oil.

Another question arising concerns the influence of the operating line on shifting within the characteristic of the compressor, particularly whether there is a risk of compressor pumping. The following diagram on the basis of the actually measured compressorcharacteristic may elucidate this aspect.

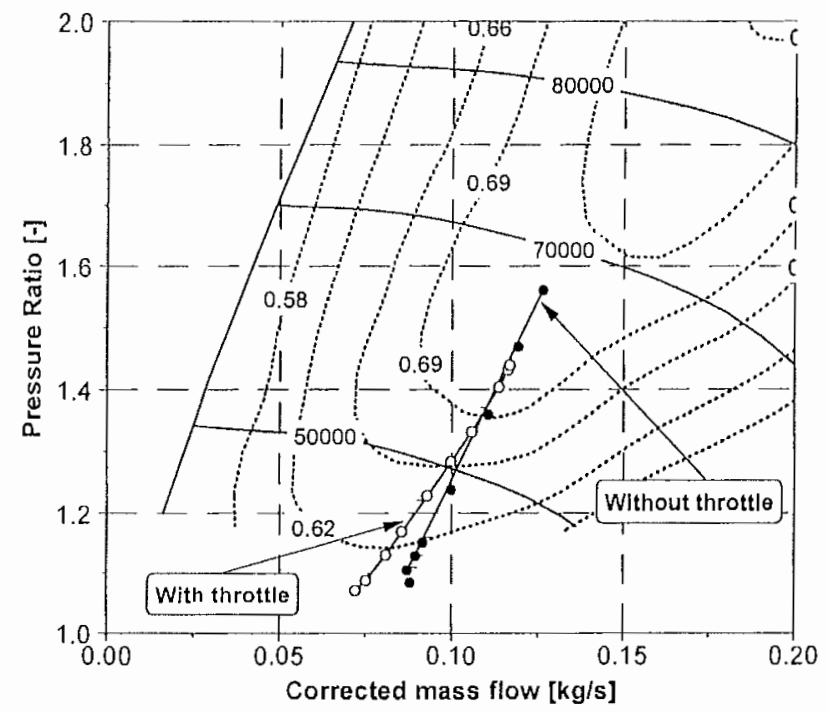

Fig.5: Characteristics of the compressor of the turbocharger with both operating lines, with and without throttling. Turbo RPM (solid line) and compression efficiency (dotted line) are plotted parameters

\section{Throttling after compressor of turbocharger}

Placing the throttle after the compressor, preferably even after the inter-cooler avoids to potential disadvantage of generating a depression which may cause an oil-leakage. On top of it, the throttling flap is smaller, the throttle is more compact and easier to install into the manifold of the compressed air.

Thermodynamic calculation of this configuration leads up to very similar results, as may be seen from the following diagram for temperatures after turbine as is of primary interest in this particular case.

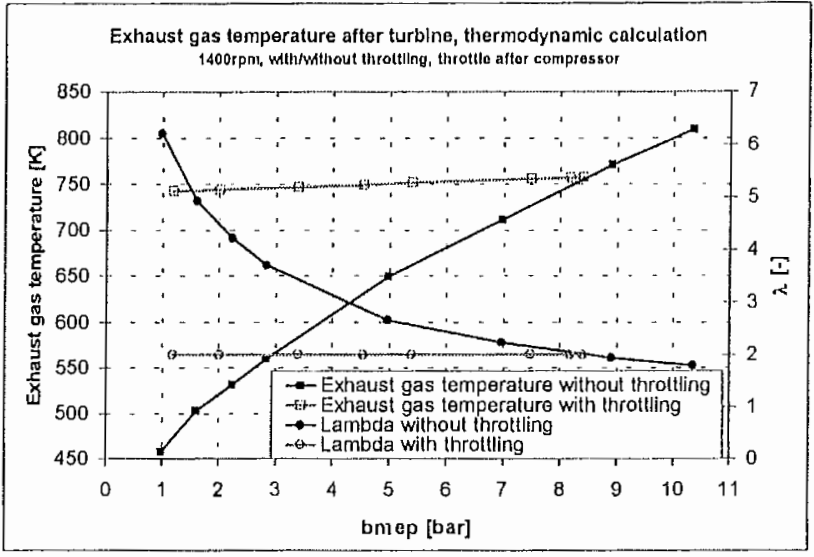

Fig.6: Exhaust gas temperature after turbine of turbocharger, if throttled after compressor (computational model).

Essentially, the result is the same as for throttling prior to the compressor. The potential increase of the exhaust temperature after turbine is obtained in the range of about $300 \mathrm{~K}$ at part load. From the viewpoint of engine-response both alternate configurations of placing the throttle are to be considered equivalent.

\section{Throttling upstream of the turbine of the turbocharger.}

Thermodynamic calculation indicated an advantage of this configuration as is shown in fig.7; however, fuel consumption is significantly higher compared to throttling of the air as is presented in fig. 8 .

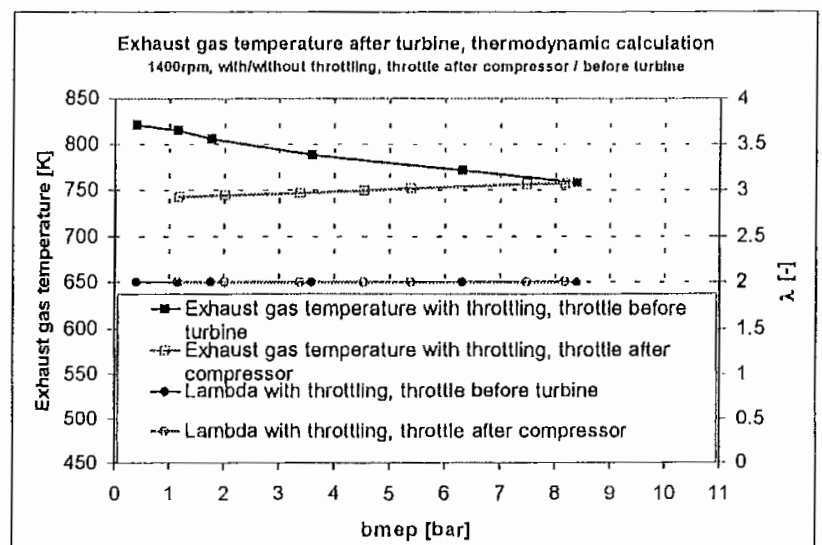

Fig.7: Increase of exhaust-temperature a) due to throttling between engine and turbine of turbocharger, and $b)$ due to throttling after compressor of turbocharger (computational model) 
Apart from disadvantages regarding design and installation, which are difficult to overcome in practice this method brings about a completely different response of the engine with respect to scavenging, character of combustion and retention of exhaust gas compared to throttling on the intake-side. On top of it there are to be expected increased soiling of the oilfilms in the engine and increased temperatures on structural components, which may constitute serious risks.

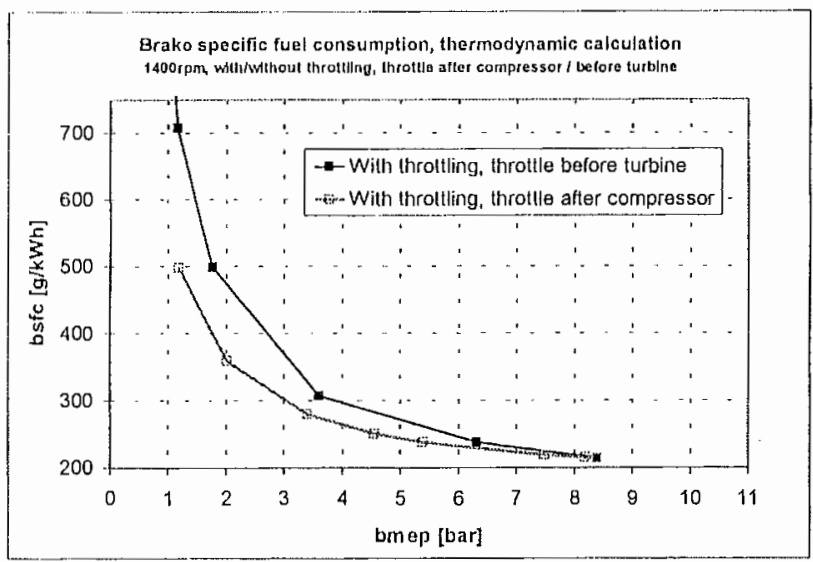

Fig. 8: Comparison of increased specific fuel consumption due to a) throttling before turbine and b) after compressor.(computational model)

\section{EXPERIMENTAL VERIFICATION}

Throttling after compressor could be evaluated experimentally; in the following diagrams experimental result are compared to result of computational simulation.

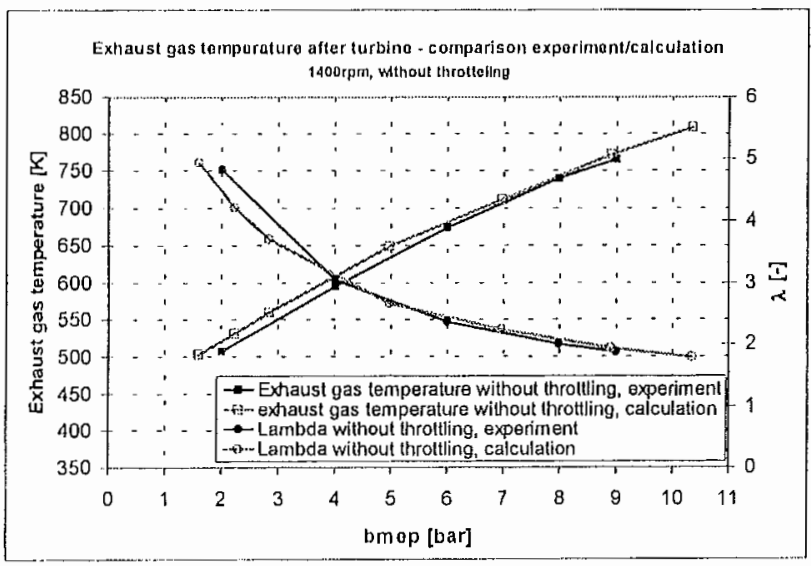

Fig.9: Exhaust gas temperature after turbine without throttling; comparison of experiment and computational simulation.

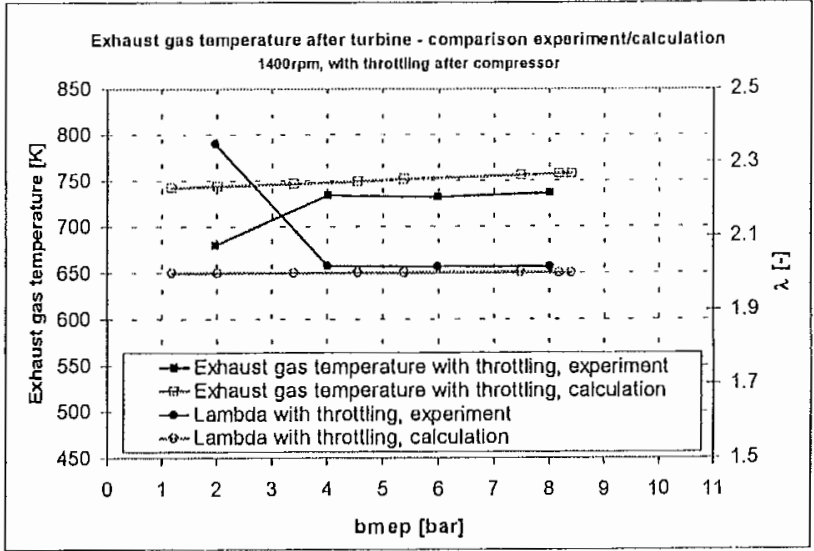

Fig. 10: Exhaust gas temperature after turbine with throttling; comparison of experiment and computational simulation.

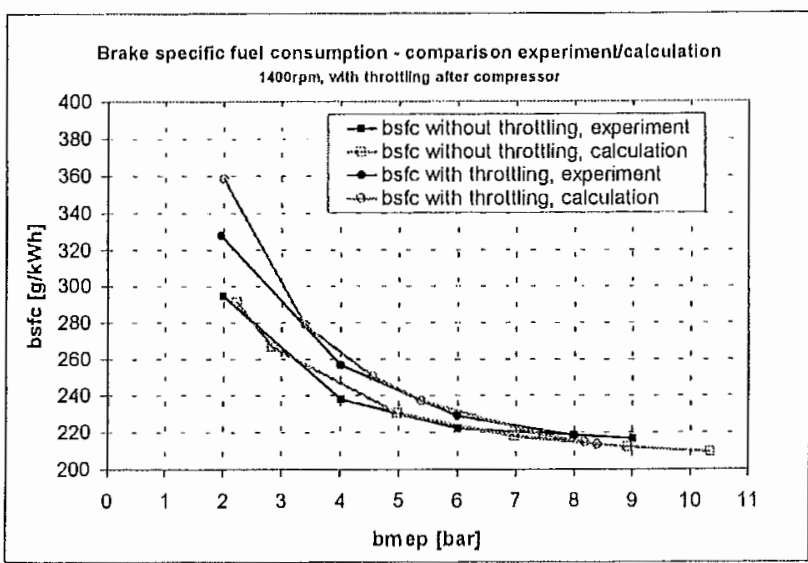

Fig.11: Specific fuel consumption with throttling after compressor; comparison of experiment and computational simulation.

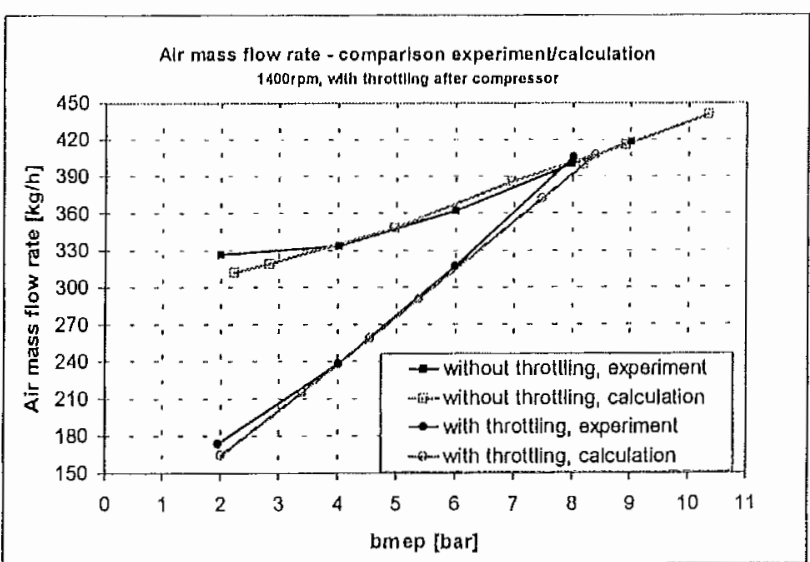

Fig. 12: Air mass flow with and without throttling; comparison of experiment and computational simulation

Generally, computations and experimental results are in very good agreement. The apparent deviation in Fig. 9, below BMEP $=4$, is explained by the fact that the throttle in this case of very low mass flow did not achieve the required pressure ratio, hence, $\lambda$ rose up to $\lambda=2.4$, instead of $\lambda=2$, and consequently exhaust gas temperature decreased. This makes clear that the throttle must be mechanically robust and quite accurate in shape. 
The engine experiments were also used to determine effects of throttling on emissions and noise, which is shown by the following three diagrams.

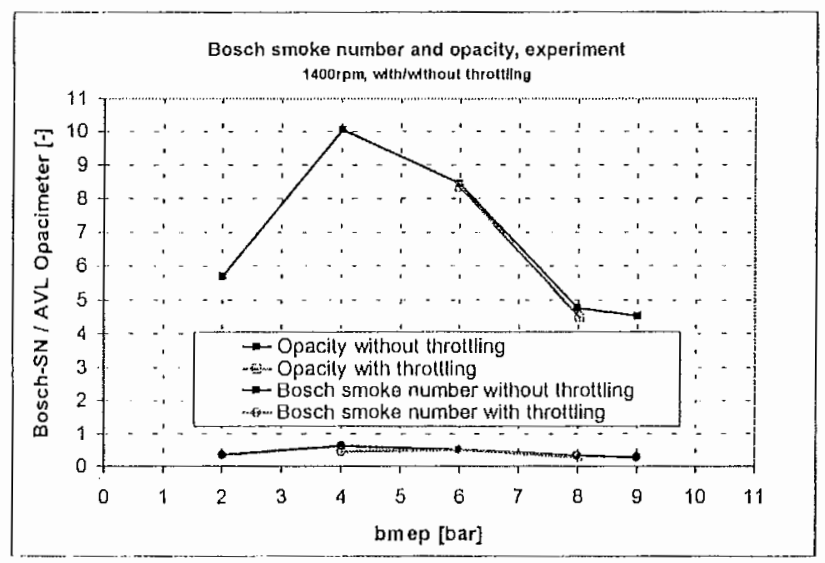

Fig. 13: Bosch smoke number and opacity with and without throttling; note the low end of load: due to throttling there was not sufficient mass flow for measuring smoke.

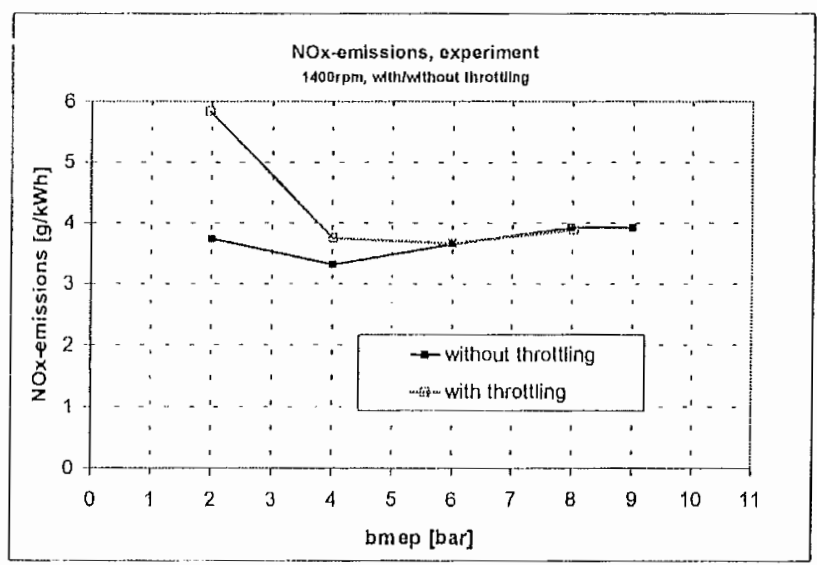

Fig. 14: NOx emissions with and without throttling.

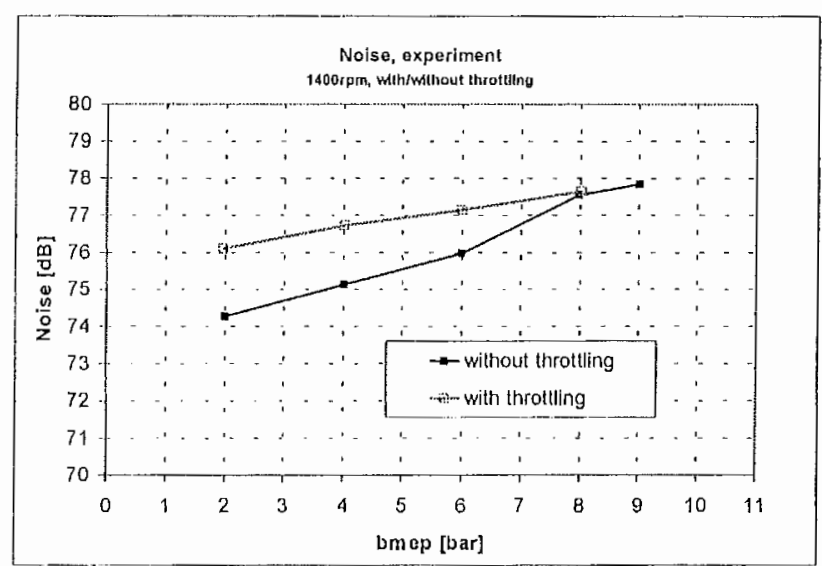

Fig. 15: Noise of combustion with and without throttling
Regarding smoke-emission there is no difference to be noticed; this was not even expected as air excess is the same. However, NOx emissions and noise of combustion exhibit minor disadvantages due to throttling. Both effects had been expected: Higher temperatures cause formation of more nitrogen-oxides and higher gradient of heat release leads necessarily to more noise.

\section{CONCEPTS OF CONTROL}

For manual or automatic control of flap-positions several strategies are available.

- At stationary operation simpie manual handling of the throttle is feasible, just to turn the flap to an fixed end-position and switch it back to the neutral position after the back-pressure is relieved - such solutions are already working for retrofit in offroad.

- With modern computer controlled engines the flap angle can be programmed in function of engine speed and load. The actuator should be able to switch between extreme positions within a tenth of a second.

- Closed loop control is also possible, based for instance on the oxygen content of the exhaust-gas using a $\lambda$-sensor [3]. This method requires an adequate control strategy for taking care of the response time of the sensor, which is in the range of 50 milliseconds.

- Flap control can also be derived from the turbocharger's waste-gate position which may be a simple mechanical solution suitable for retrofits.

- If full load is required while the operation is throttled, the flap must be moved into neutral position with only very little delay, such that full load operation is feasible without any reduction of excess air.

- Flap control may be used such that the filter is heated up to maximal exhaust temperature; after ignition-temperature of soot is achieved, throttling is reduced in order to increase oxygen for speeding up the chemical reaction, which may be reduced as well by throttling down if it begins to run too fast.

- Addition parameters for the control of the throttling operation may also be by back-pressure of the filter or the temperatures before and after the filter.

- The flap may simultaneously be used to apply also DeNOx-control-strategies in the way of exhaust gas re-circulation. This may be accomplished by means of an additional valve in the EGRconnecting manifold from exhaust to intake air; this valve being closed during regeneration.

- The flap may be used for cold start-ups, respectively for shortening down the white-smoke period, by reducing the air flow to the required minimum during that phase. 


\section{ASPECTS OF DESIGN}

Principally, the method of throttling is feasible with all Diesel engines and it is always applicable, especially in retrofit applications. Substantial force is acting on the flap of the throttle due to high pressure differences and fast changes; hence, flap and hinges must be sturdy and pressure characteristic must be such, that even at close slits fine, sensitive adjustment is sufficiently feasible.

The exhaust tube between engine and particle filter should be well insulated.

Particle-filter should exhibit little thermal inertia. Filters are preferable, that start to regenerate as soon as the surface near to the engine is already heated up in contrast to those filters which need the total surface to be heated up to required temperatures.

Further, this method should be combined with catalytic methods, either applying fuel borne catalysts or catalytic coatings. In that case temperature-increase for the onset of regeneration need only be 100-150 Centigrade, which is always feasible, i.e. from any operational condition achievable.

\section{FINAL REMARKS}

In case of mere passive methods duty cycles where regeneration conditions are not achieved can not be excluded in real world applications and can lead to major failures. An active back-up should then be available to trigger regeneration.

Original equipment manufacturers can use computer controlled injections systems to increase exhaust temperature when required - which is not advisable and even not feasible for retrofit.

Throttling of the intake, preferably downstream of the turbocharger compressor, exhibits an interesting potential, that can be applied for retrofits in combination with catalytic methods.

\section{ACKNOWLEDGMENTS}

Computations and experiments could be performed within a Swiss BUWAL technology - project aiming on further development of particle filters systems for retrofit of public transport busses. The authors wish to express their gratitude for permission to use data obtained for this publication.

\section{REFERENCES}

1. K. Pattas et al., On-Road Experience with Trap Oxidiser Systems Installed on Urban Buses, Dept. of Mechanical Engineering Aristotle University of Thessaloniki, SAE 900109

2. A. Mayer, E. Pauli; Emissions Concept for Vehicle Diesel Engine Supercharged with COMPREX, BBC, SAE 880008

3. A. Amstutz; ETH, Geregelte Abgasführung zur Senkung der Stickoxid- und Partikelemissionen beim Dieselmotor mit Comprex-Aufladung, 1991. Dissertation No. 9421

4. E. Pauli, A. Amstutz; Regelstrategie des COMPREX-aufgeladenen Dieselmotors zur Emissionsminimierung, $A B B, 3$. Aufladetechnische -Konferenz, Zürich 1988

5. Th.Gleisberg, Regelklappe in Kunststofftechnik zur Dosierung der Abgasrückführmenge in Dieselmotoren, MTZ 62(2001)4

6. F.J. Legerer, A.Mayer; Intake Throttling for Trap Regeneration, A Cursory Engineering Estimate, AKPF-home-page, "www.akpf.org" 